\title{
A Study of the Effect of Institutionalization and Spousal Bereavement on the Sense of Humor, Feeling of Alienation and Existential Regret in the Elderly
}

\author{
Rohan Pillai $^{1}$
}

\begin{abstract}
:
The present study was undertaken to examine the differences in sense of humor, feeling of alienation and existential regret between elderly persons who lived at home and those who live in old age homes, and between those elderly who had faced spousal bereavement and those who had not. Data was collected from 120 elderly persons aged 60 and above. 30 elderly from old age home, 30 elderly living at their residence, 30 elderly who have faced spousal bereavement and 30 elderly who have not faced spousal bereavement. The Multidimensional Sense of Humor Scale, The Dean's Alienation Scale and The Multidimensional Existential Regret Inventory were used to measure sense of humor, feeling of alienation and existential regret respectively. Six $t$ tests were used. After statistical analysis no significant differences were found in the sense of humor, feeling of alienation and existential regret between elderly living at home and those living in old age homes or between elderly who had faced spousal bereavement and those elderly who had not.
\end{abstract}

Keywords: Old Age, Institutionalization, Spousal Bereavement, Humor, Alienation, Existential Regret.

In the Oxford English Dictionary, humor is defined as "that quality of action, speech, or writing which excites amusement; oddity, jocularity, facetiousness, comicality, fun", (Simpson and Weiner, 1989). Humor involves cognitive, emotional, behavioral, psycho physiological, and social aspects (Martin 2001). Humor has been shown to increase lung capacity, strengthen abdominal muscles, causes reductions in cortisol, growth hormones, and epinephrine and also leads to the release of endorphins in the brain, (Tse, et al 2010). In a laboratory study of pain tolerance using cold pressor stimulation, participants in the humor group had a significant increase in pain tolerance as compared to the other groups (Weisenberg, Tepper, and Schwarzwald 1995,).

${ }^{1}$ LLB, MA (Applied Psychology), University of Mumbai, India.

(C) 2015 I R Pillai; licensee IJIP. This is an Open Access Research distributed under the terms of the Creative Commons Attribution License (http://creativecommons.org/licenses/by/2.0), which permits unrestricted use, distribution, and reproduction in any Medium, provided the original work is properly cited. 


\section{A Study of the Effect of Institutionalization and Spousal Bereavement on the Sense of Humor, Feeling of Alienation and Existential Regret in the Elderly}

Ruch (1998a) has traced the etymology of "humor," which originated in the classical Greek theory of four humors or bodily fluids (blood, phlegm, black bile, and yellow bile) that were thought to influence all aspects of bodily and psychic function and over time, humor came to refer to mood (a meaning still present when we speak of someone being in good or bad humor), and eventually it evolved into a connotation of wittiness, funniness, and laughableness, although not necessarily in a benevolent sense. (Martin 2003).

Over the years the ambit of accepted humor has evolved to include forms of humor like ridicule, social amusement, benevolent amusement, irony, satire and sarcasm. The ability to use and understand humor is generally considered as a sign of intelligence. Even in evolutionary terms, humor has gained importance in the complicated process of mate selection by showing itself to be one of the most desired traits in a potential mate.

Humor has been credited to be a healthy means of coping. Freud (1928), suggested humor to be a healthy coping mechanism. The way one appraises a problematic situation has a large influence on how one handles the situation. Adhering to an optimistic or a pessimist outlook to life has a noticeable impact on health, relationships and problem solving. Approaching stressful life situations with a healthy sense of humor allows the individual to assess the situation with a positive attitude. Humor has been described as producing a cognitive-affective shift or a restructuring of the situation so that it is less threatening, with a concomitant release of emotion associated with the perceived threat (Martin, 2003).

Relocation to an old age home and the death of a beloved spouse both involve severance of long term, lasting and meaningful ties. They are a few of the events that usually occur later in life that bring with than a sea of anxieties, insecurities and doubts. Effectively coping with them is very difficult and essential process.

\section{Relocation to an Old Age Home}

The Indian joint family system has traditionally provided natural social and psychological security to the old people. With the growing trend of the nuclear family system in India, has seen the rise of elderly populations living alone and thus factors like infirmity, coupled with an inability to self help has seen the rise both in the number of old age homes and institutionalized population. Loneliness and alienation it could be argued would be present in the elderly population both while living alone at home or when institutionalized. However some compounding factors have been observed once institutionalized.

Relocation to an old age home can produce several anxiety provoking and negative emotions as relocation incurs tremendous social, environmental and psychological change. These changes emerge from loss of contact, as they has likely been less mobile they have probably spent more time in their neighborhood than others, they will have to compromise on their lifelong living habits and patterns. Several studies have shed light on the psychological adverse effects of 


\section{A Study of the Effect of Institutionalization and Spousal Bereavement on the Sense of Humor, Feeling of Alienation and Existential Regret in the Elderly}

relocation. Research by Lieberman found out that the mortality rate of the elderly increases by $10.5 \%$ when on a to be institutionalized waiting list and by $24.7 \%$ during the first year of institutionalization

\section{Bereavement}

Bereavement means the loss by death of a loved one such as a parent, child, spouse, or close friend. For the elderly bereavement often becomes a frequent emotion to experience. Assuming one has led a healthy social life, one creates a number of friends and acquaintances, with whom one is an emotional invested and who have aged together. The gradual and eventual passing away of spouse, friends and relations is a painful rupture of the emotional support system that one has created and maintained. The influence of bereavement on one's mental makeup is severe.

The threat of facing bereavement regularly is one facet of this stage of life that makes old age challenging and relocating to an old age home under such circumstances could be difficult. Thus adequately coping with the process of relocation and bereavement especially spousal bereavement is a difficult but an essential task to overcome smoothly. Improper mitigation of the stressors caused by relocation of bereavement may lead to negative cognitions and damage self belief and self esteem. These feelings often manifest themselves into feelings of alienation and existential regret.

\section{Alienation}

The term alienation means a condition of being estranged from someone or something. In social psychology alienation refers to a person's withdrawal from society. In old age a sense of alienation may result when one is not or believes he is not ready to accept the role given to him by his family or the society that are considered age appropriate, that might not be considered to be age appropriate according to him. Often loss of control or authority over one's life or extended family creates resentment and may lead to alienation.

\section{Existential regret}

Existential regret is defined as a profound desire to go back and change a past experience in which one has failed to choose consciously or has made a choice that did not follow one's beliefs, values, or growth needs and is characterized to involve feeling of both existential anxiety and existential guilt. Existential regret in old age can be a compilation of acts of omission that in hind sight one feels would have yielded a better consequence than one that the individual finds himself in right now. As a consequence of negative life events like spousal bereavement and major life changes like relocation to an old age home, factors like existential regret can disturb the psychological wellbeing of the individual severely. 


\section{A Study of the Effect of Institutionalization and Spousal Bereavement on the Sense of Humor, Feeling of Alienation and Existential Regret in the Elderly}

\section{REVIEW OF LITERATURE}

Researches by Dixon 1980; Martin et al.1993; Shurcliff 1968 have described humor as producing a cognitive-affective shift or a restructuring of the situation so that it is less threatening, with a concomitant release of emotion associated with the perceived threat (Abel, 2002.). Shurcliff 1968 researched on the qualities of humor in the reduction in physiological arousal. Lazarus and Folkman 1984 have proposed that humor may afford the opportunity for exploring cognitive alternatives in response to stressful situations and reducing the negative affective consequences of a real or perceived threat (Abel, 2002.).

Several researches have shown sense of humor to have the qualities of a coping mechanism and is also linked with both physical and psychological well being, (Thorson \& Powell, 1993; Thorson, Powell, Sarmany-Schuller \& Hampes, 1997; Folkman \& Moskowitz, 2000).

Creecy Berg and Wright 1985 research has pointed out the contribution of physical and psychological losses that result from the change in character of economic status, physical living arrangements in the reduction of social networks and increasing amount of social isolation.

However a study, conducted by Mishra 2003, in an old age home in Kanpur, found that being engaged in various daily activities, being surrounded by same aged peers fostered positivity in the institutionalized elderly and the sample under their study did not experience loneliness

Research by Greaves and Farbus 2006 has shown that the level of social isolation and alienation to be $35 \%$ higher in institutionalized older adults that others their age.

A research conducted as early as 1967 associated bereavement with increased mortality. The research showed a 7-fold increase in mortality among bereaved spouses within the first year of their bereavement when compared with a control group. Rees W, Lutkins S 1967.

The grave implications of bereavement are brought out by the research of McAvoy that highlighted the effects of bereavement as a potential medical problem in the strict scientific sense the research also showed its potential to increase associations with morbidity and mortality and an increase in existential anxieties and regret, (McAvoy BR.1986).

Researches by Fredrickson, 2001; Fredrickson, Mancuso, Branigan \& Tugade, 2000; Ong et al, 2004 show that while very little empirical research has examined positive aspects of the bereavement coping process and adjustment outcomes, there is some evidence that positive daily emotions among the bereaved can either regulate, moderate or protect against some of the negative psychosocial reactions associated with grief (Lund, et al 2008).

Research by Carstensen, Fung \& Charles, 2003; Labouvie-Vief \& Medler, 2002; Mroczek \& Kolarz, 1998; Blanchard-Fields, 1997 has generated some evidence within the literature on emotional self regulation and the course of human development suggests that as adults age they often improve in affect optimization where they use positive emotions to reduce negative 
emotions and the end result may increase their resiliency to losses, (Lund, et al 2008). In their research Ong and colleagues (2004) found that those who experienced daily positive emotions displayer reduced experiencing of daily stress and depressive symptoms. Keltner and Bonanno (1997) also reported that bereaved persons who engaged in full-laughter were more successful in emotionally distancing themselves from grief, (Lund, et al 2008).

Hill (2005) suggests that being able to cultivate positive emotional states may be an intrapersonal resource that facilitates resilient coping in widowhood, (Lund, et al 2008).

Kuiper et al. (1993) also found the use of humor as a coping mechanism was positively correlated with the distancing and confrontive coping subscales of the Ways of Coping Scale indicating both emotion-focused and problem-focused aspects for dealing with stress, (Abel, 2002)

\section{PURPOSE}

To study the differences in the sense of humor, feeling of alienation and existential regret between the elderly living at home and those who live in old age homes, and also between those elderly who had faced spousal bereavement and those who had not.

\section{METHODOLOGY}

\section{Hypotheses}

1. There is no difference in the sense of humor between the elderly who live at home and those who reside in old age homes.

2. There is no difference in the sense of alienation between the elderly who live at home and those who reside in old age homes

3. There is no difference in the level of existential regret between the elderly who live at home and those who reside in old age homes.

4. There is no difference in the sense of humor between the elderly who have faced spousal bereavement and those who have not.

5. There is no difference in the sense alienation the elderly who have faced spousal bereavement and those who have not.

6. There is no difference in the level of existential regret between the elderly who have faced spousal bereavement and those who have not.

\section{OPERATIONAL DEFINITION OF VARIABLES}

\section{INDEPENDENT VARIABLES}

\section{Dwelling place:}

a- Home.

b- Old Age Home. 


\section{Spousal bereavement:}

$\mathrm{a}-$ Yes.

$\mathrm{b}-$ No.

\section{DEPENDENT VARIABLES}

1. Sense of humor.

2. Feeling of alienation.

3. Level of built up existential regret.

\section{CONTROL VARIABLES}

1. The respondents were all above sixty years of age

2. Respondents in from old age home had spent a minimum of one year in the institution.

3. The respondents in the spousal bereavement group had been single for over one year.

\section{Sample}

The sample consisted of 120 elderly persons aged 60 and above. 30 elderly from old age home, 30 elderly living at their residence, 30 elderly who have faced spousal bereavement and 30 elderly who have not faced spousal bereavement. (45 Females, 75 Males). The ages of the respondents ranged from 60 years to 92 years of age.

\section{Tools used}

\section{The Multidimensional Sense of Humor Scale}

The Multidimensional Sense of Humor Scale (MSHS; Thorson and Powell 1993) is a self-report measure of overall sense of humor composed of 24 statements assessing different aspects of humor including the use of humor as a coping mechanism, using humor, and recognizing and appreciating humor. Respondents indicate the degree to which each statement applies to them using a scale ranging from 1 (strongly disagree) to 5 (strongly agree). The scores are summed with higher scores indicating a better sense of humor. The internal reliability of the scale in this sample was .97 (Cronbach alpha).

\section{The Dean's Alienation Scale.}

The Dean's Alienation Scale consists of three subscales to measure powerlessness, normalness and social isolation. It combined these subscales to makeup an alienation scale. It consists of 24 items, of which 9 measure powerlessness, 6 normallessness and 9 items measure social isolation. The reliability coefficients found out by the slit half method for the powerlessness subscale have been reported to be .78 , for the normalness subscale to be .73 , and for the social isolation subscale to be .84 . The correlation coefficients among three subscales range from .81 to .91 
suggesting that it is quite feasible to consider the subscales as belonging to the same general concept. The total alienation scale has a reliability of .78. (Sharma, Uma 1980)

\section{The Multidimensional Existential Regret Inventory}

The Multidimensional Existential Regret Inventory by Samantha White \& Gary T. Reker (2007) is a 35 item 7 point Likert type scoring inventory. The MERI consists of five factorially derived dimension of existential regret. Inner Struggle $(11$ items, alpha coefficient $=.91)$. Limits on Experience $(4$ items, alpha coefficient $=.72)$. Neglecting Others $(8$ items, alpha coefficient $=$ .89). Self-Deprecation ( 7 items, alpha coefficient $=.86$ ). Undoing the Past (5 items, alpha coefficient $=.84$ ). Total Alpha coefficient of the Multidimensional Existential Regret Inventory is .95 .

\section{Procedure}

The researcher visited old age homes in Mumbai to acquire the samples for the old age home group. Three old age homes were identified and permission was obtained from the management to approach the residents. The researcher individually interviewed each participant in private and confidentiality and objectivity was ensured. No names or other personal information was recorded. The population falling in the group of residing at own residence and those facing spousal bereavement were acquired through availability. Three scales were administered to 120 subjects. The scales were administered in English, and when in doubt the researcher aided the subjects to understand the instrument. It took the researcher three months to complete the process of data collection.

\section{Statistical Analysis}

1. $t$ test.

\section{RESULTS}

$\mathbf{T}$ - tests were conducted to examine the differences between sense of humor, sense of alienation and levels of existential regret between elderly in old age homes (institutionalized) and elderly at residing at home. 
Table 1: Comparative analysis of the scores obtained on the Multidimensional Sense of Humor Scale (MSHS), by elderly living at home and the elderly living in old age homes.

\begin{tabular}{|l|l|l|l|}
\hline \multicolumn{2}{|l|}{ ELDERLY AT HOME } & \multicolumn{2}{l|}{ ELDERLY IN OLD AGE HOMES } \\
\hline Total $=1631.1$ & $\mathbf{N}=30$ & Total $=1550.1$ & $\mathbf{N}=30$ \\
\hline Mean $=54.37$ & SD $=9.62$ & Mean $=51.67$ & SD $=7.35$ \\
\hline Range $-69-36=33$ & Range $-69-40=29$ \\
\hline $\mathrm{t}(58)=0.23, \mathrm{n} . \mathrm{s}$ & \multicolumn{2}{|}{} \\
\hline
\end{tabular}

No significant difference was found between the two groups on the sense of humor, where for institutionalized elderly group ( $\bar{x}=51.67, \sigma=7.35)$ and non institutionalized elderly group $(\bar{x}$ $=54.37, \sigma=9.62$ ) conditions; $\mathrm{t}(58)=0.23$, n.s. These results suggest that both groups exhibit similar levels of a sense of humor.

Table 2: Comparative analysis of the scores obtained on the Dean Alienation Scale (DAS), by elderly living at home and the elderly living in old age homes.

\begin{tabular}{|l|l|l|l|}
\hline \multicolumn{2}{|l|}{ ELDERLY AT HOME } & \multicolumn{2}{l|}{ ELDERLY IN OLD AGE HOMES } \\
\hline Total $=2232.9$ & $\mathbf{N}=30$ & Total $=2151.9$ & $\mathbf{N}=30$ \\
\hline Mean $=74.43$ & SD=12.98 & Mean $=71.73$ & SD $=9.28$ \\
\hline Range $-103-55=48$ & Range $-90-53=37$ \\
\hline$t(58)=0.36$, n.s & \multicolumn{3}{|l}{} \\
\hline
\end{tabular}

No significant difference was found between the two groups on the sense of alienation, where for institutionalized elderly group ( $\bar{x}=71.73, \sigma=9.28)$ and non institutionalized elderly group $(\bar{x}$ $=74.43, \sigma=12.98)$ conditions; $\mathrm{t}(58)=0.36$, n.s. These results suggest that both groups exhibit relatively similar feelings of alienation. 
Table 3: Comparative analysis of the scores obtained on the Multidimensional Existential Regret Inventory (MERI), by elderly living at home and the elderly living in old age homes.

\begin{tabular}{|l|l|l|l|}
\hline \multicolumn{2}{|l|}{ ELDERLY AT HOME } & \multicolumn{2}{l|}{ ELDERLY IN OLD AGE HOMES } \\
\hline Total $=4067.1$ & $\mathbf{N}=30$ & Total $=4140.9$ & $\mathbf{N}=30$ \\
\hline Mean $=135.57$ & SD=21.12 & Mean $=138.03$ & SD $=26.89$ \\
\hline Range $-206-83=123$ & Range $-172-91=81$ \\
\hline $\mathrm{t}(58)=0.71, \mathrm{n} . \mathrm{s}$ &
\end{tabular}

No significant difference was found between the two groups on the level of existential anxiety, where for institutionalized elderly group $(\bar{x}=138.03, \sigma=26.89)$ and non institutionalized elderly group ( $\bar{x}=135.57, \sigma=21.12$ ) conditions; $\mathrm{t}(58)=0.71$, n.s. These results suggest that both groups exhibit similar levels of existential regret.

$\mathrm{T}$ test, were also conducted to examine the differences between humor, sense of alienation and levels of existential regret between elderly who have undergone spousal bereavement and those elderly who have not undergone spousal bereavement.

Table 4: Comparative analysis of the scores obtained on the Multidimensional Sense of Humor Scale (MSHS), by elderly who have faced spousal bereavement and those who have not.

\begin{tabular}{|l|l|l|l|}
\hline \multicolumn{2}{|l|}{ SPOUSAL BEREAVEMENT GROUP } & $\begin{array}{l}\text { NON SPOUSAL BEREAVEMENT } \\
\text { GROUP }\end{array}$ \\
\hline Total $=1566.9$ & $\mathbf{N}=30$ & Total $=1593.9$ & $\mathbf{N}=30$ \\
\hline Mean $=52.23$ & SD= 9.28 & Mean $=53.13$ & SD $=9.58$ \\
\hline Range $-69-40=29$ & Range $-65-30=35$ \\
\hline $\mathrm{t}(58)=0.71$, n.s. & \multicolumn{2}{|l|}{} \\
\hline
\end{tabular}

No significant difference was found between the two groups on the sense of humor, where for the spousal bereaved group $(\bar{x}=52.23, \sigma=9.28)$ and non spousal bereavement group $(\bar{x}=53.13, \sigma$ $=9.58)$ conditions; $\mathrm{t}(58)=0.71$, n.s. These results suggest that both groups are relatively similar in their utilization and appreciation of a sense of humor. 
Table 5: Comparative analysis of the scores obtained on the Dean Alienation Scale (DAS), by elderly who have faced spousal bereavement and those who have not.

\begin{tabular}{|l|l|l|l|}
\hline \multicolumn{2}{|l|}{ SPOUSAL BEREAVEMENT GROUP } & $\begin{array}{l}\text { NON SPOUSAL BEREAVEMENT } \\
\text { GROUP }\end{array}$ \\
\hline Total $=2139.9$ & $\mathbf{N}=30$ & Total $=2184$ & $\mathbf{N}=30$ \\
\hline Mean $=71.33$ & $\mathbf{S D}=8.01$ & Mean $=72.80$ & SD $=10.76$ \\
\hline Range $-80-52=28$ & Range $-103-50=53$ \\
\hline $\mathrm{t}(58)==0.55$, n.s. & \multicolumn{2}{l}{} \\
\hline
\end{tabular}

No significant difference was found between the two groups on the sense of alienation, where for the spousal bereaved group $(\bar{x}=71.33, \sigma=8.01)$ and non spousal bereavement group $(\bar{x}=72.80, \sigma$ $=10.76$ ) conditions; $\mathrm{t}(58)==0.55$, n.s. These results suggest that both groups exhibit relatively similar feelings of alienation.

Table 6: Comparative analysis of the scores obtained on the Multidimensional Existential Regret Inventory (MERI) by elderly who have faced spousal bereavement and those who have not.

\begin{tabular}{|l|l|l|l|}
\hline \multicolumn{2}{|l|}{ SPOUSAL BEREAVEMENT GROUP } & $\begin{array}{l}\text { NON SPOUSAL BEREAVEMENT } \\
\text { GROUP }\end{array}$ \\
\hline Total $=3909$ & $\mathbf{N}=30$ & Total $=4008$ & $\mathbf{N}=30$ \\
\hline Mean $=130.3$ & $\mathbf{S D}=26.89$ & Mean $=133.6$ & SD $=28.41$ \\
\hline Range $-179-91=88$ & Range $-188-89=99$ \\
\hline $\mathrm{t}(58)=0.97, \mathrm{n} . \mathrm{s}$ &
\end{tabular}

No significant difference was found between the two groups on the level of existential anxiety, where for the spousal bereaved group $(\bar{x}=130.3, \sigma=26.89)$ and non spousal bereavement group ( $\bar{x}=133.6, \sigma=28.41)$ conditions; $\mathrm{t}(58)=0.97$, n.s. These results suggest that both groups exhibit similar levels of existential regret. 


\section{A Study of the Effect of Institutionalization and Spousal Bereavement on the Sense of Humor, Feeling of Alienation and Existential Regret in the Elderly}

\section{DISCUSSION}

The hypothesis that there is no difference in the sense of humor between elderly who live at home and those who reside in old age homes cannot be rejected based on the results. One reason of this finding could be that a large number of respondents in the institutionalized group had relocated to an old age home on their own will, and had stated during pre scales administration interview that they enjoyed more independence and autonomy in the old age home than back at their home.

The results fail to reject the hypothesis of no difference in the sense of alienation between elderly who live at home and those who reside in old age homes. The institutionalized elderly did not display higher feeling of alienation as compared to non institutionalized elderly as was observed by Greaves and Farbus (2006) in their study. The institutionalized samples for this study were drawn from old age homes that encourage group activities and frequent family visits and had also incorporated sessions of group and laughter in their daily routine. This might have contributed towards the lower feeling of alienation.

The hypothesis that there is no difference in the level of existential regret between elderly who live at home and those who reside in old age homes cannot be rejected on the basis of the results. It is often the case that many older people may live in their homes with very few contacts with the society and health care services. Therefore, their relocation to an old age home and their identification with other in the same plight might give them hope, this might be one cause of lowered feeling of alienation and existential regret in the institutionalized group. It is pointed out by Findley 2003, and also Cattan et al. 2005 that group interventions aimed at alleviation of loneliness and alienation seem to be more promising than interventions targeted at individuals

The hypothesis of no difference in the sense of humor between elderly who have undergone spousal bereavement and those who have not, cannot be rejected on the basis of the foung results. Both groups displayed above average scores in humor. In this research a large number of individuals who had faced spousal bereavement lived in joint families and had not lost any significant other in the past year. Also in both the bereavement and non bereavement groups the respondents had an active social life with several of them engaging in recreational activities. Many were members of sports clubs. The individuals from both the groups had a relatively large social network. These factors might have contributed to the findings.

The data failed to reject the hypothesis that, there is no difference in the sense alienation elderly who have faced spousal bereavement and those who have not, as such the null hypothesis was retained. These findings could be the result of a strong family support of the Indian culture during bereavement, as most of the samples in the study still were living with other family members. The findings could also be attributed to the findings that, feelings of loneliness and alienation are often experienced as shameful, and older people may also fear being or becoming a burden. Thus, they are reluctant to admit them (Killeen 1998, McInnis \& White 2001.) 


\section{A Study of the Effect of Institutionalization and Spousal Bereavement on the Sense of Humor, Feeling of Alienation and Existential Regret in the Elderly}

The results failed to reject the hypothesis that there is no difference in the level of existential regret between the elderly who have faced spousal bereavement and those who have not. The results do not support the findings of McAvoy 1986 as heightened morbidity and existential regret found in his study were not replicated in the present study. These findings can also be attributed to the large social network of the respondents in both the groups and also to the fact that they live in joint families and were active in social and household activities. Fiori and her colleagues (2006) pointed out that individuals have different social networks and that each has a different effect on health. The different roles that each person plays parent, child, co-worker, churchgoer, introduce them to different networks that help them to feel socially connected and improve their sense of well-being (Population Reference Bureau).

\section{CONCLUSION}

The results of this study show that the differences in the sense of humor, feeling of alienation and of existential regret between the elderly living at home and the elderly living in old age homes were marginal and not significant. While relocation to an old age home can produce several anxiety provoking and negative emotions as relocation incurs tremendous social, environmental and psychological change, the findings from this study failed to indicate the impact of relocation on sense of humor feeling of alienation and existential regret. A large number of respondents were institutionalized by free will, and had options to reside elsewhere. It remains for future researches to study the phenomena of relocating to an old age home by choice in the India.

The study did not bring out significant differences in the sense of humor, feeling of alienation and levels of existential regret between the elderly who have faced spousal bereavement and those who have not faced spousal bereavement. A healthy social network and a joint family unit were the most influential factors towards these findings in both the groups.

\section{LIMITATIONS}

1. The sample size was small.

2. Baselines for sense of humor, alienation and existential regret were not considered

3. Interaction effects were not studied.

4. Physical ailments of the sample were not considered.

5. Quality of life before relocation, in the old age home group, and marriage satisfaction before spousal bereavement in the spousal bereavement group were not considered.

6. This study was only conducted on elderly people in Mumbai thus it difficult to determine whether these results are truly representative of the nation's elderly people. 


\section{A Study of the Effect of Institutionalization and Spousal Bereavement on the Sense of Humor, Feeling of Alienation and Existential Regret in the Elderly}

\section{SUGGESTIONS}

1. Future research can explore the relationship of humor on feeling of loneliness and quality of life.

2. Research can be carried on as to why in a large population like India that provides opportunity to form social networks an increasing number of elderly are opting to relocate to old age homes.

3. The cognitive abilities of the elderly in relation to their sense of humor is another area that can be investigated.

4. Other methods of assessing humor may be utilized like the The Situational Humor Response Questionnaire (Martin and Lefcourt 1984) that allows for the assessment of the individual's capacity to respond to a variety of situations, or The Cartoon Punch line Production Test CPPT, (Köhler and Ruch 1993) that assesses the individual's quantitative and qualitative humor creation abilities.

\section{REFERENCES}

Abel, M.H., 2002. Humor, stress, and coping strategies. Humor: International Journal of Humor Research.

Allport, G. W. (1961). Pattern and growth in personality. New York: Holt, Rinehart \& Winston.

Cattan, M., White, M., Bond, J., \& Learmouth, A. (2005). Preventing social isolation and loneliness among older people: a systematic review of health promotion interventions. Ageing and society, 25(01), 41-67.

Craik, K. H., \& Ware, A. P. (1998). Humor and personality in everyday life. In W. Ruch (Ed.), The sense of humor: Explorations of a personality characteristic (pp. 63-94). New York:Mouton de Gruyter.

Creecy, R.F, Berg, W.E, Wright, R. Loneliness among the elderly: A causal approach. J. Gerontol. 1985.

Freud, S. (1928) Humour. International Journal of Psychoanalysis.

Dixon, Norman F.1980 Humor: A cognitive alternative to stress. In Spielberger, C. D. and I. G. Sarason (eds.), Anxiety and Stress, Vol. 7. Washington, DC:Hemisphere.

Robyn A. Findlay (2003). Interventions to reduce social isolation amongst older people: where is the evidence?. Ageing and Society, 23, pp 647-658. doi:10.1017/S0144686X03001296.

Folkman S, Moskowitz JT Am Psychol. 2000.

Freud, S. (1928) Humour. International Journal of Psychoanalysis.

Goldstein \& P. E. McGhee (Eds.), The psychology of humor: Theoretical perspectives and empirical issues. New York: Academic Press.

Greaves, C.J., \& Farbus, L. (2006). Effects of creative and social activity on the health and wellbeing of socially isolated older people: Outcomes from a multi-method observational study. Journal of the Royal Society of Health. 


\section{A Study of the Effect of Institutionalization and Spousal Bereavement on the Sense of Humor, Feeling of Alienation and Existential Regret in the Elderly}

Henderson, A. S., R. Scott, and D.W. Kay. 1986. "The Elderly Who Live Alone: Their ental Health andSocialRelationships.”Australian\&NewZealand Journal of Psychiatry.

J. A. Simpson and E. S. C. Weiner, Eds., The Oxford English Dictionary, Clarendon Press, Oxford, UK, 2nd edition, 1989.

Kuiper, N. A., \& Martin, R. A. (1998). Is sense of humor a positive personality characteristic? In W. Ruch (Ed.), The sense of humor: Explorations of a personality characteristic. New York: Mouton de Gruyter.

Kuiper, N. A., Martin, R. A., \& Olinger, L. J. (1993). Coping humour, stress, and cognitive appraisals. Canadian Journal of Behavioural Science.

Lazarus, Richard S. and Susan Folkman 1984 Stress, Appraisal, and Coping. New York: Springer.

Lefcourt, H. M. (2001). Humor: The psychology of living buoyantly. New York: Kluwer Academic.

Lieberman, M., Tobin, S., \& Slover, D. (1971). The effects of relocation on long-term geriatric patients. (Final Rep. Proj. No. 17-1328). Illinois Dept. of Health \& Committee on Human Development, Univ. Chicago, Chicago, 1971.

Lund, D. A., Utz, R., Caserta, M. S., \& de Vries, B. (2008). Humor, Laughter \& Happiness in the Daily Lives of Recently Bereaved Spouses. Omega, 58(2), 87.

M. Weisenberg, I. Tepper, and J. Schwarzwald, "Humor as a cognitive technique for increasing pain tolerance," Pain, vol. 63, no. 2, 1995.

Martin R. Humor, laughter, and physical health: methodological issues and research findings. Psychol Bull. 2001.

Martin, R. A. (2003). Sense of humor. In S. J. Lopez \& C. R. Snyder (Eds.), Positive psychological assessment: A handbook of models and measures. Washington, DC: American Psychological Association.

Martin, R.A., Puhlik-Doris, P., Larsen, G., Gray, J., Weir, K., 2003. Individual differences in uses of humor and their relation to psychological well-being: development of the Humor Styles Questionnaire. Journal of Research in Personality.

Martin, Rod A. and Herbert M. Lefcourt 1983 Sense of humor as a moderator of the relation between stressors and moods. Journal of Personality and Social Psychology.

Martin, Rod A., Nicholas A. Kuiper, L. Joan Olinger, and Kathryn A. Dance 1993 Humor, coping with stress, self-concept, and psychological well-being. Humor: International Journal of Humor Research.

Mimi M. Y. Tse, Anna P. K. Lo, Tracy L. Y. Cheng, Eva K. K. Chan, Annie H. Y. Chan, and Helena S. W. Chung, "Humor Therapy: Relieving Chronic Pain and Enhancing Happiness for

Mc Avoy, B.R. (1986). Death and bereavement, British Medical Journal.

Mishra, A.J., A Study of Loneliness in an Old Age Home in India: A case of Kanpur. Indian Journal of Gerontology. 17 (1\&2). (2003). 
Nezu, A. M., Nezu, C. M., \& Blissett, S. E. (1988). Sense of humor as a moderator of the relation between stressful events and psychological distress: A prospective analysis. Journal of Personality and Social Psychology.

Older Adults," Journal of Aging Research, vol. 2010, Article ID 343574, 9 pages, 2010. doi:10.4061/2010/343574

Ong AD, Bergeman CS, Bisconti TL. The role of daily positive emotions during conjugal bereavement. Journal of Gerontology: Psychological Sciences. 2004.

Population Reference Bureau Today's Research on Aging | No. 17 | June 2009

Rees, W. D. , \& C. G. Lutkins. Mortality of bereavement. British Medical Journal . 1967.

Ruch, W. (1992). Assessment of appreciation of humor: Studies with the 3 WD humor test. In C. D. Spielberger \& J. N. Butcher (Eds.), Advances in personality assessment (Vol. 9) Hillsdale, NJ: Erlbaum.

Seligman, M.E.P., 2005. Positive psychology, positive prevention, and positive therapy.

In: Snyder, C.R., Lopez, S.J. (Eds.), Handbook of Positive Psychology. Oxford University Press, Oxford.

Shurcliff, Arthur 1968 Judged humor, arousal, and the relief theory. Journal of Personality and Social Psychology.

Suls, J. M. (1972). A two-stage model for the appreciation of jokes and cartoons. In J. H. Goldstein \& P. E. McGhee (Eds.), The psychology of humor: Theoretical perspectives and empirical issues. New York: Academic Press.

Svebak, S. (1996). The development of the Sense of Humor Questionnaire: From SHQ to SHQ6. Humor, 9.

Thorson JA, Powell FC J Clin Psychol. Development and validation of a Multidimensional Sense of Humor Scale. 1993.

Thorson, J. A., Powell, F. C., Sarmany-Schuller, I., \& Hampes, W. P. (1997). Psychological health and sense of humor. Journal of Clinical Psychology.

Van Baarsen, B., T. A. B. Snijders, J. H. Smit, and M. A. J. van Duijn. 2001. "Lonely But Not Alone: Emotional Isolation and Social Isolation asTwo Distinct Dimensions of Loneliness in Older People." Educational and Psychological Measurement. 